\title{
The VANI2-ERA hindeast of sea-level residuals: atmospheric forcing of sea-level variability in the Mediterranean Sea (1958-2008)
}

\author{
GABRIEL JORDÀ ${ }^{1}$, DAMIÀ GOMIS ${ }^{1}$ and ENRIQUE ÁLVAREZ-FANJUL ${ }^{2}$ \\ ${ }^{1}$ IMEDEA (UIB-CSIC), Departament d'Ecologia i Recursos Marins, Carrer Miquel Marquès 21, 07190 Esporles, Spain. \\ E-mail: gabriel.jorda@uib.es \\ ${ }^{2}$ Puertos del Estado, Avenida Partenón 10, 28042 Madrid, Spain.
}

\begin{abstract}
SUMMARY: The hindcasts of residual sea surface are very useful tools for the design of infrastructures and coastal management applications, as well as for scientific studies on sea-level variability. In this paper we present VANI2-ERA, a new hindcast of residual sea surface covering the Mediterranean Sea and a sector of the NE Atlantic Ocean with a spatial resolution of $1 / 6^{\circ} \times 1 / 4^{\circ}$. VANI2-ERA was obtained with a barotropic version of the HAMSOM model forced with a dynamical downscaling of the ERA40 reanalysis spanning the period 1958-2008. This new hindcast represents an update of the well-known HIPOCAS hindcast, which has been the reference dataset for the last few years. VANI2-ERA has been extensively validated with tide gauge observations distributed all around Southern Europe and compared with four other hindcasts, including HIPOCAS. The new hindcast shows smaller root mean square errors, higher correlation and higher variance reduction than any previous hindcasts at most stations. However, its performance is poorer than HIPOCAS in reproducing the magnitude of extreme events. Residual sea surface trends were also obtained and their uncertainty was assessed by means of a comparison between VANI2-ERA and HIPOCAS for the common period 1958-2001. Differences of up to $0.4 \pm 0.1 \mathrm{~mm} \mathrm{yr}^{-1}$ between the two datasets are derived from the differences between the ERA40 and NCEP atmospheric reanalyses. The VANI2-ERA hindcast was also used to compare the variability of the period 1998-2008 with past decades, obtaining that the standard deviation of sea-level residuals has been 5-10\% lower than for the period 1958-2008. The period 1998-2008 also shows a $20 \%$ reduction in the magnitude of positive extreme events, while negative extreme events have not changed significantly with respect to past decades. Finally, the trends computed for the period 1998-2008 are slightly positive $(+0.11 \pm 0.04 \mathrm{~mm}$ $\mathrm{yr}^{-1}$ ) compared with the clearly negative trends obtained for the period 1958-2008.
\end{abstract}

Keywords: sea level, Mediterranean, atmospheric forcing, hindcast.

RESUMEN: EL HINDCAST VANI2-ERA DE RESIDUOS DE NIVEL DEL MAR: FORZAMIENTO ATMOSFÉRICO DE LA VARIABILIDAD DEL NIVEL DEL MAR en el MediterRÁNeo (1958-2008). - Los hindcasts de residuos de nivel del mar son una herramienta muy útil para el diseño de infraestructuras y aplicaciones de gestión costera, así como para estudios sobre la variabilidad del nivel del mar. En este trabajo se presenta VANI2-ERA, un nuevo hindcast de residuos de nivel del mar que cubre todo el Mediterráneo y un sector del Atlántico NE con una resolución espacial de $1 / 6^{\circ} \times 1 / 4^{\circ}$. VANI2-ERA se ha obtenido con una versión barotropa del modelo HAMSOM forzado con una regionalización dinámica del reanálisis ERA40 que abarca el periodo 1958-2008. Este nuevo hindcast representa una actualización del conocido hindcast HIPOCAS, el cual ha sido la referencia de múltiples estudios durante los últimos años. VANI2-ERA se ha validado exhaustivamen-te con observaciones de mareógrafos distribuidos por toda Europa del sur y comparado con los resultados de otros cuatro hindcasts, incluido HIPOCAS. El nuevo hindcast muestra errores cuadráticos medios más pequeños, mayores correlaciones y una mayor reducción de la varianza que el resto de hindcasts analizados. Sin embargo, su calidad reproduciendo la magnitud de eventos extremos es menor que HIPOCAS. Se han obtenido también tendencias de la componente atmosférica de nivel del mar y se ha estimado su incertidumbre comparando VANI2-ERA con HIPOCAS para el periodo común 1958-2001. Las diferencias entre ambos son de hasta $0.4 \pm 0.1 \mathrm{~mm}^{2}$ año ${ }^{-1}$ y se atribuyen a discrepancias entre los reanálisis atmosféricos ERA40 y NCEP. VANI2-ERA se ha utilizado también para estudiar la variabilidad de nivel del mar durante el periodo 1998-2008 y compararla con las últimas décadas. Los resultados muestran que este periodo se ha caracterizado por una reducción del 5-10\% en la desviación estándar respecto al periodo completo 1958-2008. También se ha observado una reducción del $20 \%$ en la magnitud de eventos extremos positivos y prácticamente ningún cambio en los eventos extremos negativos. Finalmente, el periodo 1998-2008 muestra pequeñas tendencias positivas $(+0.11 \pm 0.04 \mathrm{~mm}$ año ${ }^{-1}$ ) frente a las claras tendencias negativas obtenidas para todo el periodo 1958-2008.

Palabras clave: nivel del mar, Mediterráneo, forzamiento atmosférico, hindcast. 


\section{INTRODUCTION}

Long-term homogeneous oceanographic databases have become a major need for scientific studies covering subjects ranging from the description of processes to climate change, and for management applications dealing with offshore industries, fisheries, insurance businesses and tourism. In particular, sea level is a key variable for coastal development. Some examples are beach erosion due to sea-level rise, flooding events related to storm surges, damage to harbour structures caused by wind waves and salt intrusions in fresh water streams and reservoirs (see e.g. Nicholls and Leatherman 1994). All these effects are particularly important for Southern Europe, where a large part of the economy relies directly or indirectly on shore activities.

The processes contributing to sea-level variability are tides, atmospheric mechanical forcing, thermosteric expansion/compression and mass addition/ removal. The relative importance of each component depends on the region and the time scales of interest. In particular, the atmospheric mechanical forcing exerted by the atmospheric pressure and wind is responsible for the storm surges, with relatively fast sea-level variations (with time scales ranging from hours to a few days) reaching large amplitudes in coastal areas. The atmospheric forcing also induces a large part of the variability at intra-seasonal time scales. Marcos and Tsimplis (2007) found that it accounts for about a half of the amplitude of the Mediterranean sea-level annual cycle and is also responsible for the observed semi-annual signal. At longer time scales, Tsimplis et al. (2005) suggested that the reduced sea level trends observed in Southern Europe between 1960 and 2000 in comparison with global-scale observations were caused by changes in the atmospheric forcing.

One of the first attempts to generate a long-term homogeneous database of the atmospheric component of sea-level variability was carried out in the framework of the EU-funded project "Hindcast of Dynamic Processes of the Ocean and Coastal Areas of Europe (HIPOCAS)". The 44-year hindcast (1958-2001) generated during HIPOCAS covered the Mediterranean Sea and a sector of the NE Atlantic Ocean (Ratsimandresy et al., 2008). It was obtained using a barotropic ocean model forced by atmospheric sea-level pressure (SLP) and wind stress resulting from a dynamical downscaling of the NCEP reanalysis. The quality of the HIPOCAS hindcast has been assessed by several authors (e.g. Ratsimandresy et al. 2008, Pascual et al. 2008).

The high quality of the hindcast has allowed numerous scientific studies. Tsimplis et al. (2005) used the hindcast to show that eliminating the atmospheric signal from tide gauge records significantly increases the consistency between Southern European sea-level trends. Gomis et al. (2006) quantified the atmospheric contribution of the variability of the flow through the Strait of Gibraltar. Gomis et al. (2008) also studied the low-frequency Mediterranean Sea level variability induced by atmospheric pressure and wind. Finally, Marcos et al. (2009) characterized the sealevel extremes in Southern Europe.

The HIPOCAS database has also been used for many management applications with important socioeconomic implications, such as the design of harbour piers and other coastal infrastructures, the determination of flood risk areas, the design of shipyards and the study of climate evolution over the last few decades. Unfortunately, the period covered by the HIPOCAS hindcast (1958-2001) is becoming obsolete for some management applications and for scientific studies focusing on recent sea level changes.

The goal of this paper is to present an updated hindcast of the atmospheric contribution to sea level variability for Southern Europe. Since this contribution (i.e. excluding tides and the steric and mass components) is often referred to as residual sea surface (RSS), we will adopt this terminology to refer to the diagnosed parameter. The new hindcast presented in this work covers the period 1958-2008 and our aim is to update it regularly in the near future. A crucial issue when generating a new database is its validation. Here the new hindcast is validated against tide gauge observations at different frequency bands and during different periods. Additionally, the quality of the hindcast is compared with other available hindcasts in order to assess the relative improvement afforded by this new product. Finally, we take advantage of the extended period of the hindcast to describe the evolution of the RSS in Southern Europe during the last decade.

The paper is organized as follows. The description of the model, the forcings and the data used for the validation are presented first. Then, the new hindcast is thoroughly validated against tide gauge observations and compared with other hindcasts. Next, the RSS statistics of the last decade are analysed and compared with those of previous decades. Finally, all results are discussed and the main conclusions are outlined.

\section{MATERIALS AND METHODS}

\section{The numerical model}

The modelling system set-up used to generate the new hindcast is very similar to the one used by Ratsimandresy et al. (2008) in HIPOCAS and the one run by Puertos del Estado for the Spanish sea-surface elevation operational forecasting system (ÁlvarezFanjul et al. 1997). The three systems are based on the barotropic version of the HAMSOM ocean model (Backhaus 1983). HAMSOM is a three-dimensional primitive equation model that uses the Boussinesq and hydrostatic approximations. The spatial integration is performed on an Arakawa $\mathrm{C}$ grid with a $\mathrm{Z}$ coordinate system in the vertical. In the model integration, the pressure gradient and the vertical diffusivity terms are integrated using a semi-implicit scheme, while the momentum advection and the horizontal diffusion terms use an explicit one. 


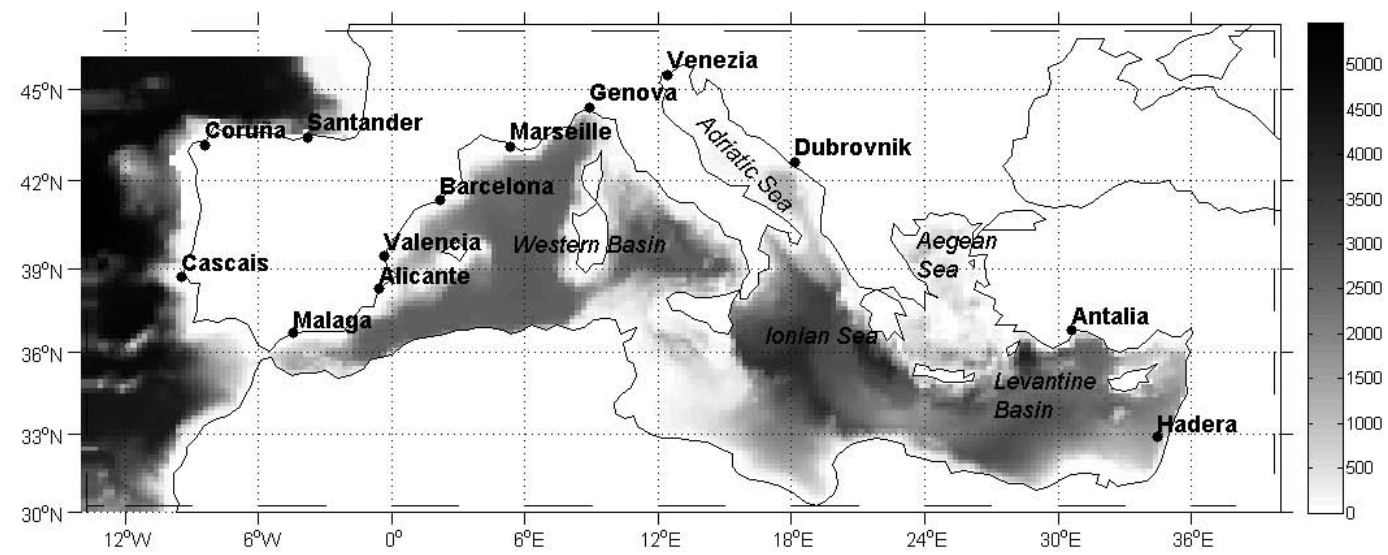

FIG. 1. - Ocean model domain and bathymetry. The dots show the location of the tide gauges used for the model validation.

The model domain covers the whole Mediterranean basin and part of the northeastern Atlantic Ocean (Fig. 1 ), with a grid resolution of $10^{\prime}$ in latitude and $15^{\prime}$ in longitude. Concerning the model spatial resolution, Ratsimandresy et al. (2008) have shown that increasing the resolution to 5' (closer to state-of-the-art operational ocean circulation models of the Mediterranean Sea) does not significantly improve the results. The model is 6-hourly forced by SLP and 10-m winds from an atmospheric model. It is worth commenting that the time evolution of the SLP averaged over the global ocean is added to the model outputs a posteriori. This value, constant in space but not in time, is required to transfer the information from the global ocean to the regional limited area model. The model outputs are stored every hour to properly represent the storm surge events.

The only difference between the system configuration of the new hindcast and HIPOCAS is in the atmospheric forcing, which comes from the dynamical downscaling of two different reanalyses carried out with two different advanced atmospheric models. This fact has the added value of enabling the quantification of the uncertainties of the RSS products derived from the atmospheric forcings. On one hand, HIPOCAS used a dynamical downscaling of the NCEP/NCAR global reanalysis obtained with the REMO atmospheric model (Sotillo et al. 2005). The REMO domain covered Europe and North Africa with a spatial resolution of $0.5^{\circ}$ (roughly $50 \mathrm{~km}$ ); the ocean model was forced by 6-hourly atmospheric fields (winds and sea level pressure). On the other hand, the atmospheric forcing used in the new hindcast comes from the ARPERA dataset, developed at Météo-France/CNRM by Michel Déqué (pers. comm.) and described in Herrmann and Somot (2008) and Tsimplis et al. (2009). ARPERA was obtained using a global stretched-grid version of the ARPEGE-Climate model (Déqué and Piedelievre 1995, Déqué 2007). Although the model is global, the stretched grid allows an increased resolution over the Mediterranean, reaching $\sim 40-50 \mathrm{~km}$ over the selected domain. The dynamical downscaling is carried out in spectral form: the large scales of ARPEGE-Climate model are forced to follow the synoptic chronology of a large scale reanalysis (Simmons and Gibson 2000) by using a spectral nudging technique, while the small scales $(<250 \mathrm{~km})$ are free. For the period 1958-2001, fields from the ERA40 reanalysis (Gibson et al. 1997) are used to drive the ARPEGE-Climate model. Between 2002 and 2008, fields from the European Centre for Medium-Range Weather Forecasts (ECMWF) analysis are used, their resolution $\left(0.5^{\circ} \sim 55 \mathrm{~km}\right)$ being downgraded to ERA40 resolution $\left(1.125^{\circ} \sim 125 \mathrm{~km}\right)$ in order to ensure the consistency between the 1958-2001 and 2002-2008 periods. No noticeable jump between the two periods has been identified (S. Somot, pers. comm.). The atmospheric fields used to force the ocean model are available 6-hourly, as in HIPOCAS.

\section{Tide gauge observations}

Hourly sea-level values from 15 tide gauges located in the Mediterranean Sea and on the Atlantic Iberian coasts were used in the analysis (Fig. 1). The time series are made available through the ESEAS website (http:// www.eseas.org) and the web sites of various national services. The records span different time periods ranging from 3 to 48 years and were found to have different quality. Marcos et al. (2009) carried out a careful quality control of the records used here, including searching for datum shifts, outliers and time drifts. The last step of the data processing was the removal of tides; they were estimated and removed from the records on a yearly basis by means of a harmonic analysis carried out with the standard program t-tide (Pawlowicz et al. 2002).

\section{Experiment description}

The results of the new hindcast (hereafter referred to as the VANI2-ERA hindcast) are compared with four other available hindcasts in order to assess the relative improvement (if any) provided by the new product. The first one is the HIPOCAS hindcast (Ratsimandresy et al. 2008), which has already been described. The second one is the Dynamic Atmospheric Correc- 
tion (DAC) product that is currently delivered by the Archiving, Validation, and Interpretation of Satellite Oceanographic data (AVISO) system (http://www.aviso.oceanobs.com/) used to correct satellite altimetry. DAC is based on the global barotropic model MOG2D (Carrère and Lyard 2003), which uses a finite-element space discretization. This approach allows the resolution to be increased in regions with a steep bathymetry and in shallow areas. The model resolution ranges from $400 \mathrm{~km}$ in the deep ocean to $20 \mathrm{~km}$ in coastal areas. The DAC product combines the MOG2D results for frequencies higher than 20 days and the classical inverted barometer correction for lower frequencies. The model is forced by atmospheric pressure and 10-m wind fields from the ECMWF analysis, which have a temporal resolution of $6 \mathrm{~h}$ and a spatial resolution of $0.25^{\circ} \times 0.25^{\circ}$ (see http://www.aviso.oceanobs.com/en/ data/products/index.html for more details).

The third hindcast used in the comparison is the classical isostatic inverted barometer (IB) correction. Although it cannot be strictly considered as a hindcast, it has been commonly used to remove the atmospherically generated ocean signal from tide gauges or along-track altimeter data prior to their mapping. The IB approach is also often used as a measure of atmospherically-induced sea level when no ocean model is available, because only atmospheric pressure fields are needed to estimate the IB approach:

$$
I B=\left(P-P_{r e f}\right) / \rho g
$$

where $\rho$ is the mean density of the water, $g$ is the acceleration of gravity, $\mathrm{P}$ is the atmospheric pressure at each grid point and $\mathrm{P}_{\text {ref }}$ is the mean pressure over the entire model domain. The IB was computed from the same 6-h ECMWF atmospheric pressure fields that are used to force the MOG2D model.

Finally, the hindcast presented in Jordà et al. (2011) is also used in the comparison. That hindcast (hereafter referred to as ARP3) is basically the same as the VANI2-ERA hindcast, the only difference being that the atmospheric forcing is generated using an older version of the ARPEGE/Climate model: while in VANI2-ERA the atmospheric forcing is obtained from the version 4.6 of ARPEGE/Climate, in ARP3 version 3.0 is used. The difference between the two versions of the ARPEGE/Climate model lies in some physical parameterizations and in the configuration of the nudging technique used to downscale the ERA reanalysis.

\section{HINDCAST VALIDATION}

\section{Basic statistics}

The validation of the VANI2-ERA hindcast is performed by comparing the model outputs with tide gauge observations. In order to isolate the atmospheric signal in the tide gauge records as much as possible, we remove the non-atmospheric contribution to the seasonal cycle. This contribution is basically caused by the steric component (i.e. the seasonal thermal expansion/contraction) and is the dominant contribution to the seasonal cycle (Marcos and Tsimplis 2007). Since no temperature series collocated with the tide gauges are available, a first approach to the non-atmospheric signal of tide gauge records can be obtained by subtracting the collocated VANI2-ERA output from each observed record. The steric seasonal cycle is then estimated by fitting a harmonic signal to the residuals (observations minus VANI2-ERA) and removed from each original tide gauge record.

The model skills are evaluated in terms of the root mean square difference (RMSE) and the correlation coefficient between tide gauge records and the collocated output of the hindcast. Another measure of the skills, in this case relative to the variance of the signal, is given by the variance reduction, which is defined as:

$$
\text { varred }=100 \cdot\left(1-\frac{\operatorname{var}\left(\eta_{\text {obs }}-\eta_{\text {model }}\right)}{\operatorname{var}\left(\eta_{\text {obs }}\right)}\right)
$$

where 'var' denotes variance and $\eta_{\text {obs }}$ and $\eta_{\text {model }}$ are the observed and modelled sea level, respectively. It is easy to show that if the model perfectly matches the observations in terms of correlation and variance, the variance of the difference (model-observations) approaches zero and hence the variance reduction approaches $100 \%$. Conversely, if the model does not reproduce the observed variability, the variance reduction approaches $0 \%$.

The computations are carried out using daily values, since some of the hindcasts used in the comparison were not available at a higher frequency. All values were obtained for the period common to the four hindcasts, in order to be comparable. Results are shown in Table 1. The RMSE of VANI2-ERA shows an averaged value of $5.1 \mathrm{~cm}$, with a minimum value of $3.6 \mathrm{~cm}$ at Genova and a maximum error of $8.1 \mathrm{~cm}$ at Venezia. The correlation is high at all tide gauge stations, with an averaged value of 0.84 and a minimum value of 0.74 . VANI2-ERA explains on average $70 \%$ of the variability of the de-seasoned tide gauge series. The maximum explained variance is at the Bilbao and Genova stations, where the hindcast explains more than $80 \%$ of the variance of the de-seasoned records. Conversely, at Cascais and Venezia the hindcast only explains about $55 \%$ of the variance.

Compared with HIPOCAS, we find that VANI2ERA improves the results at most stations in terms of RMSE, correlation and variance reduction. However, the differences between the two runs are small: the relative improvement in terms of RMSE is only about $3 \%$ of the standard deviation of the signals. The improvement of VANI2-ERA is only noticeable at Hadera station, where it reduces the RMSE by about $11 \%$ in comparison with the HIPOCAS RMSE.

The results obtained for the other hindcasts show that the IB approximation is the worst one for all the 
TABLE 1. - Comparison of model outputs with tide gauge observations in terms of rms error, correlation and variance reduction. All magnitudes were computed from daily values and for the common period covered by all the hindcasts (1958-2001). The best result for each tide gauge is highlighted (in bold).

\begin{tabular}{|c|c|c|c|c|c|}
\hline Station & VANI2-ERA & HIPOCAS & DAC & IB & ARP3 \\
\hline \multicolumn{6}{|c|}{ RMS Error $(\mathrm{cm})$} \\
\hline Bilbao & 4.33 & 4.36 & 5.54 & 5.81 & 4.94 \\
\hline Santander & 5.90 & 5.67 & 6.66 & 6.84 & 6.48 \\
\hline Gijon & 5.64 & 5.56 & 6.64 & 7.01 & 6.14 \\
\hline A Coruña & 5.80 & 5.92 & 7.00 & 7.46 & 6.43 \\
\hline Cascais & 5.78 & 5.79 & 6.04 & 6.16 & 6.05 \\
\hline Málaga & 5.13 & 5.09 & 5.58 & 6.09 & 5.30 \\
\hline Alicante & 4.09 & 4.37 & 5.29 & 6.14 & 4.52 \\
\hline Valencia & 5.00 & 4.91 & 5.78 & 6.57 & 5.21 \\
\hline Barcelona & 4.32 & 4.46 & 5.25 & 5.91 & 4.60 \\
\hline Marseille & 5.06 & 4.85 & 6.12 & 6.79 & 5.23 \\
\hline Genova & 3.66 & 3.74 & 4.91 & 5.58 & 3.86 \\
\hline Venezia & 8.14 & 8.38 & 9.01 & 9.68 & 8.22 \\
\hline Dubrovnik & 5.18 & 5.19 & 6.52 & 7.10 & 5.38 \\
\hline Antalya & 4.88 & 5.04 & 5.94 & 6.56 & 5.12 \\
\hline Hadera & 4.26 & 4.76 & 5.65 & 6.27 & 4.43 \\
\hline \multicolumn{6}{|l|}{ Correlation } \\
\hline Bilbao & 0.91 & 0.91 & 0.86 & 0.84 & 0.89 \\
\hline Santander & 0.86 & 0.87 & 0.82 & 0.80 & 0.83 \\
\hline Gijon & 0.89 & 0.89 & 0.86 & 0.84 & 0.86 \\
\hline A Coruña & 0.88 & 0.88 & 0.83 & 0.81 & 0.85 \\
\hline Cascais & 0.76 & 0.76 & 0.73 & 0.72 & 0.73 \\
\hline Málaga & 0.78 & 0.79 & 0.74 & 0.67 & 0.77 \\
\hline Alicante & 0.88 & 0.87 & 0.79 & 0.71 & 0.85 \\
\hline Valencia & 0.84 & 0.84 & 0.78 & 0.70 & 0.82 \\
\hline Barcelona & 0.88 & 0.87 & 0.81 & 0.75 & 0.86 \\
\hline Marseille & 0.84 & 0.86 & 0.76 & 0.69 & 0.83 \\
\hline Genova & 0.90 & 0.90 & 0.81 & 0.75 & 0.89 \\
\hline Venezia & 0.74 & 0.72 & 0.67 & 0.60 & 0.73 \\
\hline Dubrovnik & 0.85 & 0.85 & 0.75 & 0.68 & 0.84 \\
\hline Antalya & 0.79 & 0.77 & 0.67 & 0.57 & 0.76 \\
\hline Hadera & 0.81 & 0.76 & 0.66 & 0.55 & 0.79 \\
\hline
\end{tabular}

Variance reduction (\%)

\begin{tabular}{llllll} 
Bilbao & $\mathbf{8 2 . 9 3}$ & 82.75 & 72.14 & 69.30 & 77.85 \\
Santander & 72.79 & $\mathbf{7 4 . 9 1}$ & 65.39 & 63.45 & 67.23 \\
Gijon & 78.39 & $\mathbf{7 9 . 0 0}$ & 70.01 & 66.57 & 74.40 \\
A Coruña & $\mathbf{7 7 . 2 1}$ & 76.24 & 66.84 & 62.34 & 72.02 \\
Cascais & $\mathbf{5 7 . 7 7}$ & 55.60 & 53.82 & 52.05 & 53.71 \\
Málaga & 61.39 & $\mathbf{6 1 . 9 7}$ & 54.27 & 45.50 & 58.79 \\
Alicante & $\mathbf{7 7 . 9 0}$ & 74.73 & 63.02 & 50.12 & 72.96 \\
Valencia & 70.24 & $\mathbf{7 1 . 3 1}$ & 60.23 & 48.55 & 67.65 \\
Barcelona & $\mathbf{7 6 . 6 7}$ & 75.17 & 65.51 & 56.26 & 73.48 \\
Marseille & 70.74 & $\mathbf{7 3 . 0 3}$ & 57.10 & 47.23 & 68.67 \\
Genova & $\mathbf{8 0 . 9 1}$ & 80.12 & 65.71 & 55.69 & 78.84 \\
Venezia & $\mathbf{5 4 . 6 5}$ & 51.92 & 44.53 & 35.93 & 53.75 \\
Dubrovnik & $\mathbf{7 1 . 6 2}$ & 71.42 & 55.04 & 46.57 & 69.31 \\
Antalya & $\mathbf{6 1 . 6 8}$ & 59.14 & 43.39 & 30.86 & 57.90 \\
Hadera & $\mathbf{6 4 . 7 7}$ & 56.17 & 38.14 & 23.83 & 61.95 \\
\hline
\end{tabular}

stations. Its RMSE is, on average, $30 \%$ larger than for VANI2-ERA. The IB approach performs especially badly at Alicante, Genova and Hadera, where its RMSE is over $40 \%$ larger than for VANI2-ERA. The correlation is also the worst at all stations, but differences are not as large as for the RMSE. The DAC hindcast is better than the IB approach, which is an expected result because DAC includes wind effects. However, it is clearly worse than VANI2-ERA or HIPOCAS, with a 20\% larger RMSE on average. Correlation is also greater in general, but the variance reduction provided by $\mathrm{DAC}$ is $17 \%$ lower than the variance reduction provided by VANI2-ERA. Finally, the overall skills of ARP3 are better than those of DAC, but worse than those of the VANI2-ERA or HIPOCAS.

An interesting result is that all hindcasts show the best/worse skills at the same stations, independently of the ocean and/or atmospheric model used to generate the hindcast. Thus, the results for Genova (Venezia) are the best (worse) for all hindcasts (see Table 1).

\section{Hindcast representativity at different frequency bands}

The hindcasts of RSS are used for a broad range of applications focusing on different frequency bands (from daily to interannual variability). Therefore, when looking at the performance of the hindcast it is important to quantify the extent to which the modelled RSS can explain the observed variance at different frequency bands. With this aim, both the model outputs and the observational records were filtered (using running averages) to isolate the 1-3 days band (i.e. linked to storm surges), the 3-30 days band (intra-monthly variability) and the 30-365 days band (intra-annual variability), and the variance reduction was computed for each band (Table 2). For the 1-3 days band the hindcast explains much less variance than for the total time series: the variance reduction is lower than $65 \%$ at most stations, being especially low at Cascais (26\%) and Gijón (32\%), while the maximum variance reduction is obtained at A Coruña (67\%) and Genova (71\%). For the 3-30 days band the averaged variance reduction is slightly higher than for the whole record, with the exception of Alicante and Barcelona, where the variance reduction is slightly smaller (see Table 2). The case of Venezia is especially interesting: the intra-monthly variance explained by the hindcasts is about $80 \%$, while for the whole record it was only $55 \%$. In the 30-365 days band the atmospheric forcing explains less variance at Alicante and Cascais, while at Barcelona, Marseille and Valencia the explained variance is about 5\% larger than for the full record.

TABLE 2. - Variance reduction (\% of the variability) at different frequency bands provided by VANI2-ERA at different tide gauge locations.

\begin{tabular}{lcccc}
\hline Station & Full record & 1-3 days & 3-30 days & 30 days-1 year \\
\hline Bilbao & 82.93 & 43.07 & 85.59 & 84.74 \\
Santander & 72.79 & 60.73 & 77.23 & 74.79 \\
Gijon & 78.39 & 31.95 & 79.31 & 79.07 \\
A Coruña & 77.21 & 67.21 & 83.06 & 79.49 \\
Cascais & 57.77 & 26.06 & 62.89 & 49.51 \\
Málaga & 61.39 & 61.39 & 61.28 & 62.89 \\
Alicante & 77.90 & 60.67 & 72.86 & 74.90 \\
Valencia & 70.24 & 61.92 & 72.36 & 76.93 \\
Barcelona & 76.67 & 55.37 & 74.45 & 81.86 \\
Marseille & 70.74 & 52.26 & 72.31 & 77.18 \\
Genova & 80.91 & 70.55 & 82.88 & 65.96 \\
Venezia & 54.65 & 53.75 & 82.03 & 56.11 \\
Dubrovnik & 71.62 & 58.13 & 80.10 & 69.84 \\
Antalya & 61.68 & 64.07 & 63.42 & 60.42 \\
Hadera & 64.77 & 56.94 & 64.26 & 64.43 \\
\hline
\end{tabular}




\section{Extreme events}

The characterization of extreme events is a key contribution of an RSS database, since extreme total sea level values (either positive or negative) are mainly caused by higher-than-usual values of SLP and/or winds. Moreover, a long and homogeneous record of sea-level extremes is needed to compute return periods or return levels, which are crucial parameters for the design of coastal infrastructures. To check the performance of VANI2-ERA regarding extreme events, the 99th percentile (positive extremes) and the 1st percentile (negative extremes) were computed from hourly time series of tide gauge observations and from the collocated VANI2-ERA output. The results, shown in Figure 2, reveal that the hindcast underestimates the (absolute) values of the positive and negative extreme events at most locations. Concerning the positive extreme events, the hindcast values are on average a $10 \%$ smaller than the observed values. The largest differences between model and observations are obtained at Cascais $(-6 \mathrm{~cm})$, Dubrovnik $(-5 \mathrm{~cm})$, Marseille $(-4 \mathrm{~cm})$ and Venezia $(-7 \mathrm{~cm})$, while the smallest differences are obtained at A Coruña $(-0.5 \mathrm{~cm})$ and Genova $(-0.6 \mathrm{~cm})$. For the negative extreme events the differences are greater: the hindcast underestimates their magnitude by $17 \%$ on average. The greatest differences are found at Cascais $(-8 \mathrm{~cm})$, Hadera $(-7 \mathrm{~cm})$ and Santander $(-7$ $\mathrm{cm})$, while the smallest differences are found at Genova $(-2 \mathrm{~cm})$ and Valencia $(-2 \mathrm{~cm})$.

Figure 2 also shows the results obtained for HIPOCAS. The hindcast extreme values is also lower than for the observations, but slightly closer to them than those obtained from VANI2-ERA. For positive extreme events the HIPOCAS underestimation is about $7 \%$ when averaged over all the stations, while for negative events it is about $13 \%$ (that is, about 3\%-4\% smaller than for VANI2-ERA). Looking at particular stations we find that for positive extremes VANI2-ERA performs similarly to HIPOCAS in the Atlantic locations, while in the Mediterranean HIPOCAS is clearly better. For negative extremes HIPOCAS is better everywhere except at Gijón. A comparison with the outputs of the other hindcasts was also performed (results are not shown). All of them performed worse than VANI2ERA at reproducing extreme events, with ARPERAv3 and DAC performing similarly and the IB approach giving the greatest underestimations.

\section{Stationarity of hindcast errors}

The quality of the VANI2-ERA hindcast is now assessed as a function of time. To do this the RMSE is computed from hourly data in a sliding window of fiveyear periods. The results for the four longest records (covering more than 40 years) are shown in Figure 3. It can be seen that the RMSE significantly changed over time at A Coruña and Santander, with changes greater than $50 \%$ (more than $3 \mathrm{~cm}$ ) in comparison with the
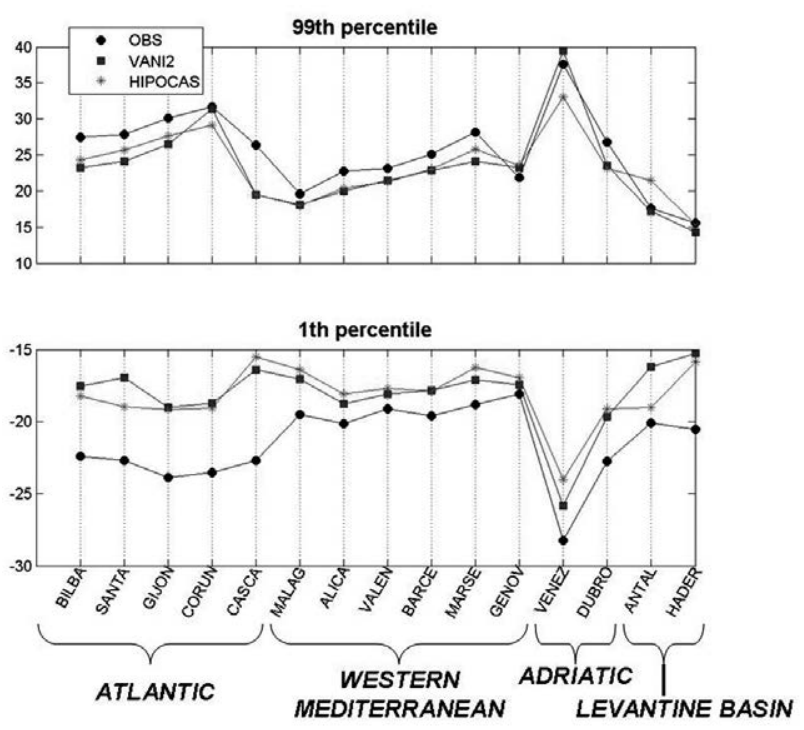

FIG. 2. - Comparison of extreme percentiles at different tide gauge locations. (Top) 99th percentile, corresponding to extreme positive events. (Bottom) 1st percentile, corresponding to extreme negative events. Observations are quoted as black dots, VANI2-ERA values by squares and HIPOCAS values by stars. The stations have been organized according to their location, starting from the Atlantic, then those in the western Mediterranean and finally those in the eastern Mediterranean. A colour version of this figure may be found in the online electronic manuscript

RMSE averaged over the whole period. It is interesting to notice that RMSE at these two locations show a similar evolution during the period 1970-2000: the quality of the hindcast increased during the period 1970-1985 and then decreases to reach a maximum RMSE in 1990. The time evolution of the RMSE at Dubrovnik is less marked, with changes below $20 \%$ in comparison with the mean value (i.e. variations of $1 \mathrm{~cm}$ in comparison with a mean value of $5 \mathrm{~cm}$ ). Finally, the error of the hindcast at Alicante is almost stationary in time: changes are lower than $12 \%$ of the mean value (variations of $0.5 \mathrm{~cm}$ in comparison with a mean value of $3.8 \mathrm{~cm}$ ).

The time evolution of the quality of the HIPOCAS hindcast was also assessed for the sake of completeness (see dotted lines in Fig. 3). The RMSE of HIPOCAS follows the same evolution as for VANI2-ERA at all locations, so the difference between the RMSE of the two hindcasts is always close to the mean value reported previously (in Table 1 ).

In order to explain the evolution of the RMSE, we checked possible changes in the variability of sea level. Figure 3 shows that the time evolution of the sea-level standard deviation (STD) resembles the time evolution of the RMSE, especially in the case of Alicante and Dubrovnik, suggesting that the latter could be caused (at least partially) by the former. (For a given percentage of variance reduction or a given value of the correlation between two series, an increase in the variance of the signal will imply an increase in the RMSE.) 

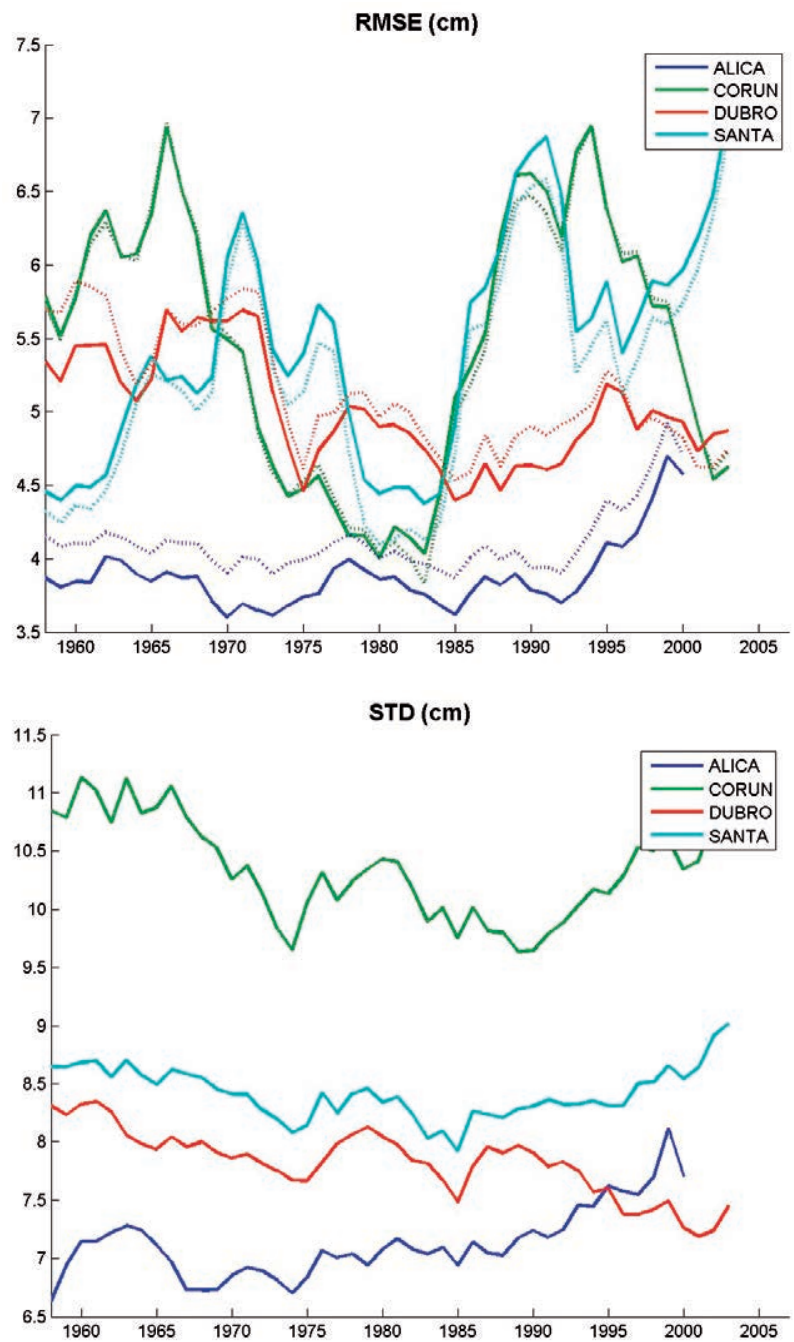

FIG. 3. - (Top) Time evolution of RMSE (cm) for VANI2-ERA hindcast (solid lines) and the HIPOCAS hindcast (dotted lines) at the tide gauge locations with the longest records. (Bottom) Time evolution of the STD of sea-level residuals obtained from the same tide gauge records. A colour version of this figure may be found in the online electronic manuscript

\section{STATISTICAL ANALYSIS OF THE PERIOD 1998-2008}

A major advantage of VANI2-ERA in comparison with HIPOCAS is that it covers the period until 2008, whereas HIPOCAS only covers the period until 2001. Therefore, it is worth investigating whether in the last decade the atmospheric contribution to sea level has undergone any significant change in comparison with previous decades in Southern Europe.

\section{Sea-level variability at intra-seasonal scales}

The sea-level variability can be quantified at each gridpoint by computing the STD of the model time series. In particular, the STD computed for the whole period (Fig. 4A) can be compared with the STD computed for different decades (Fig. 4B-F). In order to focus on intra-seasonal scales we use daily values of de-seasoned and detrended time series. Moreover, we represent the difference between the STD of each decade in comparison with the STD computed for the whole hindcast period.

Figure 4 shows that in Southern Europe the atmospherically induced sea-level variability has a clear latitudinal gradient: minimum values are found in the African Atlantic area and in the Levantine basin, with STD values of about $5 \mathrm{~cm}$, while in the northern part of the Atlantic sector the STD reaches $11 \mathrm{~cm}$. This distribution is in clear correspondence with the distribution of atmospheric pressure variability, as shown by Gomis et al. (2008). Large STD values (up to $11.9 \mathrm{~cm}$ ) are also found in the northern Adriatic, but in this case they are forced by the wind, rather than by the variability of the atmospheric pressure (Cushman-Roisin et al. 2001).

Analysing the STD in 10-year periods reveals that sea-level variability has not been constant in time, but the differences between periods are lower than $10 \%$ of the mean STD value. During the periods 1958-1968 and 1988-1998 the variability was higher than on average, particularly in the northern and southern parts of the model domain (respectively). Conversely, during the years 1968-1978 the variability was 5\% lower than average in the Atlantic sector. Finally, the period $1998-2008$ is the one with the lowest STD values in the western and central Mediterranean: 10\% lower than average.

\section{Trends and decadal variability}

The spatial distribution of atmospherically induced sea-level trends obtained from the VANI2-ERA database (Fig. 5A) shows negative values over the whole domain. The largest trends are found in the western and central Mediterranean, with values reaching $-0.65 \pm 0.04$ $\mathrm{mm}$ year ${ }^{-1}$. The smallest trends are found in the Levantine basin $\left(-0.31 \pm 0.02 \mathrm{~mm}\right.$ year $\left.^{-1}\right)$ and in the African Atlantic area $\left(-0.23 \pm 0.04 \mathrm{~mm}\right.$ year $\left.^{-1}\right)$.

Further insight on the decadal evolution of sea level is achieved by computing the trends for different 10-year periods (Fig. 5B-D). During the period 1958-1968 trends were mostly negative (mean values of $-0.24 \pm 0.03 \mathrm{~mm}$ year $^{-1}$ ) but exhibited a clear east to west gradient: positive trends of up to $+1.15 \pm 0.26 \mathrm{~mm}$ year $^{-1}$ are found in the Levantine basin, while negative trends of up to $-2.66 \pm 0.46 \mathrm{~mm}^{\text {year }}{ }^{-1}$ are found in the Atlantic area. During the periods 1968-1978 and 1978-1988 the trends were negative over the whole domain, being especially high during the second period, when they had a mean value of $-1.95 \pm 0.2 \mathrm{~mm}$ year $^{-1}$ and reached maximum values of up to $-3.3 \pm 0.52 \mathrm{~mm}$ year $^{-1}$ in the Adriatic and Aegean seas. During the period 1988-1998 the situation reversed, with high positive trends over the whole model domain. The mean value was $+2.31 \mathrm{~mm}^{\text {year }}{ }^{-1}$, reaching maximum values 
STD-whole period

A

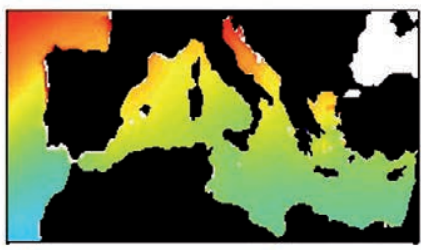

$\Delta \operatorname{STD}(\%)$ 1968-1978

$\mathrm{C}$

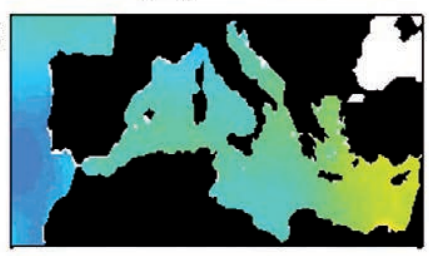

$\Delta \mathrm{STD}(\%)$ 1988-1998

E

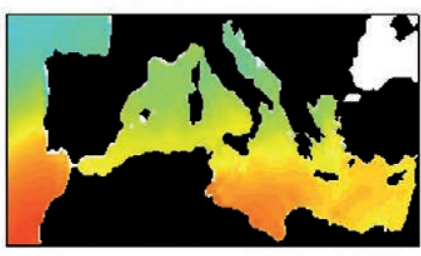

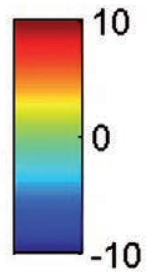

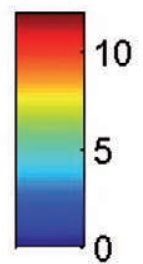

0

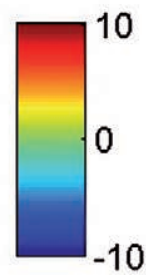

$\Delta \mathrm{STD}(\%)$ 1958-1968

B
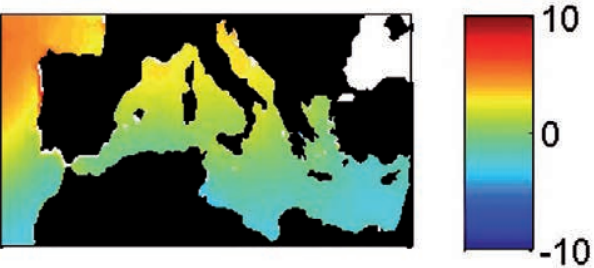

$\Delta \mathrm{STD}(\%)$ 1978-1988

D

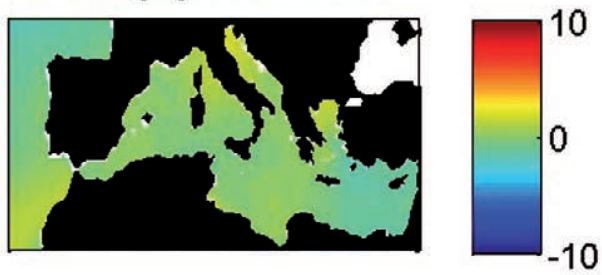

$\Delta \mathrm{STD}(\%)$ 1998-2008

$\mathrm{F}$

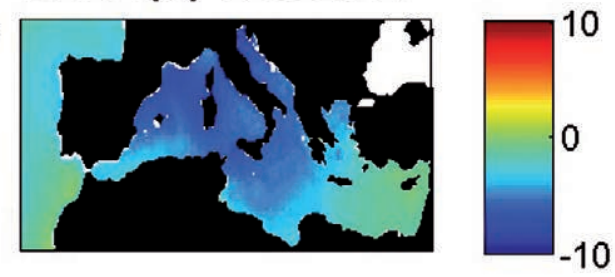

FIG. 4. - Sea level variability from the VANI2-ERA hindcast. A, STD $(\mathrm{cm})$ estimated for the whole period 1958-2008. B-F, percentage of change in the STD computed for different 10-year periods with respect to the whole period shown in A. A colour version of this figure may be found in the online electronic manuscript

\section{Whole period}

A

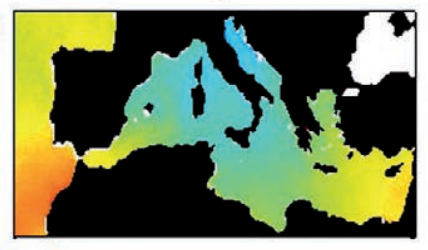

1968-1978

C

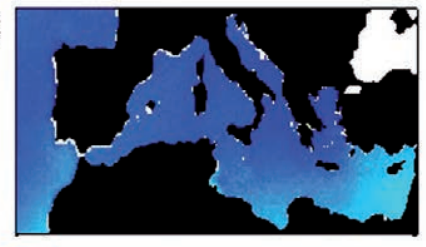

1988-1998

E

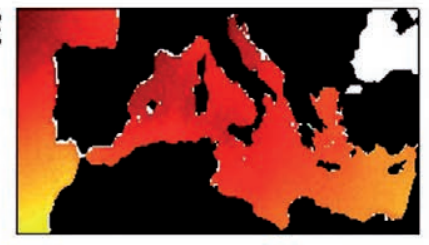

1958-1968
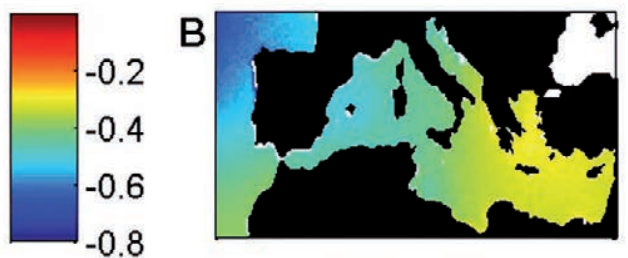

1978-1988

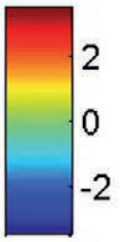

$\mathrm{D}$

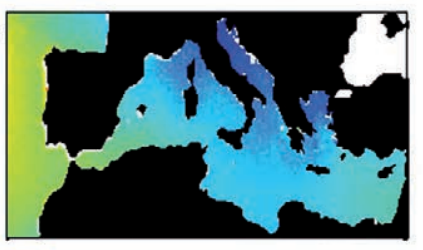

1998-2008

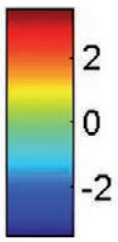

F

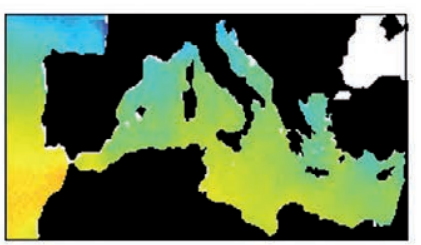

Trend (mm/year)

FIG. 5. - Spatial distribution of atmospherically induced sea-level trends $\left(\mathrm{mm} \mathrm{yr}^{-1}\right)$ from the VANI2-ERA hindcast. A, trend obtained for the whole period 1958-2008. B-F, trends computed for different 10-year periods. Note that the colour scale in A is different from the other panels. A colour version of this figure may be found in the online electronic manuscript 


\section{TREND 1958-2008}

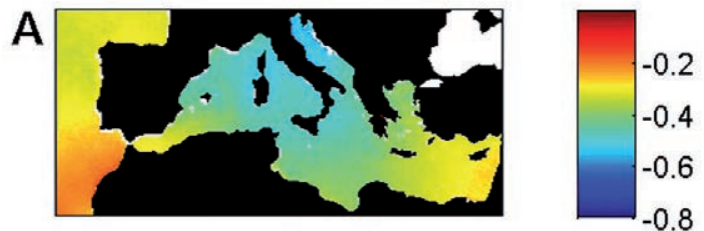

TREND 1958-2001

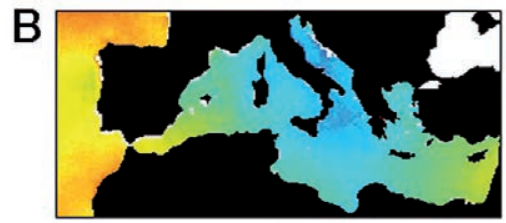

Trend difference [1958-2008]-[1958-2001]
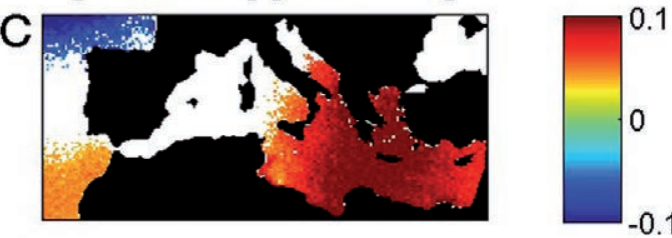

FIG. 6. - Atmospherically induced sea-level trends $\left(\mathrm{mm} \mathrm{yr}^{-1}\right)$ from the VANI2-ERA hindcast computed for different periods: A, 19582008; B, 1958-2001; C, differences between the two maps. Areas where differences are not statistical significant have been masked. A colour version of this figure may be found in the online electronic manuscript

of up to $+3.98 \pm 0.34 \mathrm{~mm}$ year $^{-1}$ in the western Mediterranean, the Adriatic and to the northwest of the Atlantic sector. It is worth noting that during this period the spatial distribution of the trends is very close to that of the period 1968-1978, but with the opposite sign. Fi- nally, the period 1998-2008 was characterized by small trends (mean value of $+0.11 \mathrm{~mm}^{-1} \mathrm{yr}^{-1}$ ), exhibiting a latitudinal gradient from the $+0.85 \pm 0.21 \mathrm{~mm} \mathrm{year}^{-1}$ obtained on the African coasts to the $-0.74 \pm 0.34 \mathrm{~mm}$ year ${ }^{-1}$ obtained in the Atlantic, northwestern Mediterranean, Adriatic and Aegean regions.

The marked decadal variability shown above suggests that the trends computed for the last 40 to 50 years may be affected by the inclusion of the recent years in the trend estimation. Most sea-level trends reported so far for the Mediterranean region have been obtained from the HIPOCAS dataset and therefore refer to the period 1958-2001. Now the VANI2ERA database can be used to compare the trends obtained for that period with the trends obtained for the expanded period 1958-2008. At first sight the two distributions of trends look similar (Fig. 6): negative values over the whole domain, larger trends in the western and central Mediterranean and smaller trends in the Atlantic sector and in the Levantine basin. However, some differences can be appreciated (Fig. $6 \mathrm{C})$. If the whole period is used, the trends obtained in the eastern Mediterranean are up to $0.15 \pm 0.03 \mathrm{~mm}$ year $^{-1}$ less negative than for the period 1958-2001 (i.e. there is a reduction in the trend magnitude of $\sim 25 \%$ ). Conversely, in the northern part of the Atlantic sector trends are $-0.12 \pm 0.04 \mathrm{~mm}$ year $^{-1}$ more negative for the expanded period (i.e. there is an increase of 40-60\% in the magnitude of the trends). In the other regions, the trend estimation is less sensitive to the period used for the computation. In the African Atlantic area, for instance, the differences between the two periods are only $0.05 \pm 0.03 \mathrm{~mm} \mathrm{year}^{-1}$ (i.e. $\sim 15 \%$ reduction) and in the western Mediterranean and northern Adriatic the differences are almost negligible.
Whole period

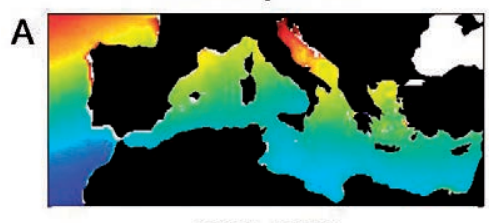

1968-1978

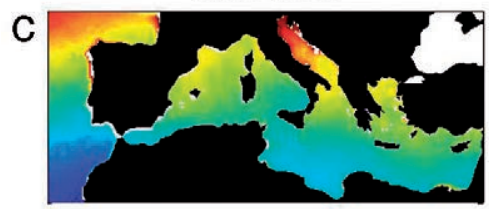

1988-1998

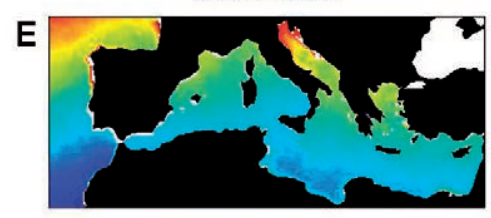

1958-1968

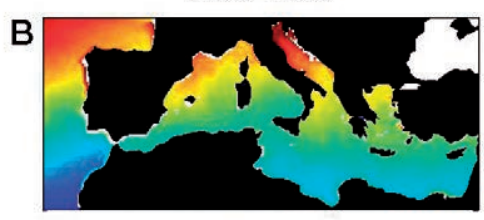

1978-1988

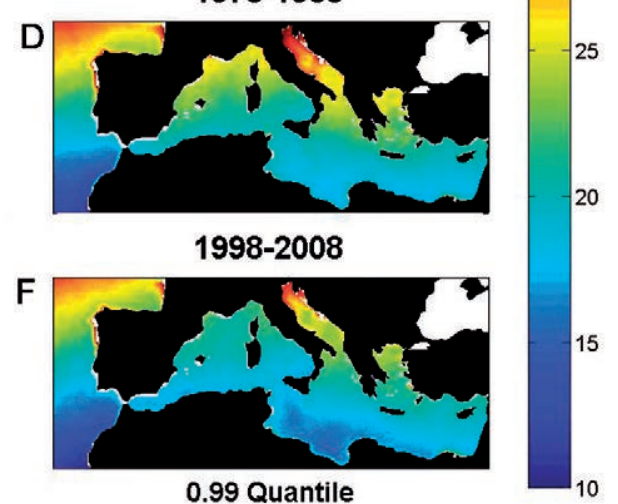

FIG. 7. - Spatial distribution of the $99^{\text {th }}$ percentile of RSS time series from the VANI2-ERA hindcast. A, $99^{\text {th }}$ percentile obtained for the whole period 1958-2008. B-F, $99^{\text {th }}$ percentile computed for different 10-year periods. A colour version of this figure may be found in the online electronic manuscript 

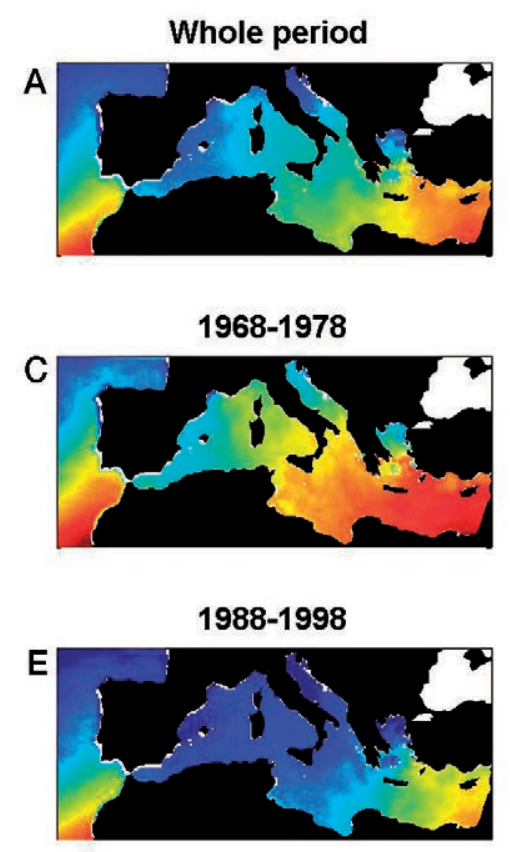

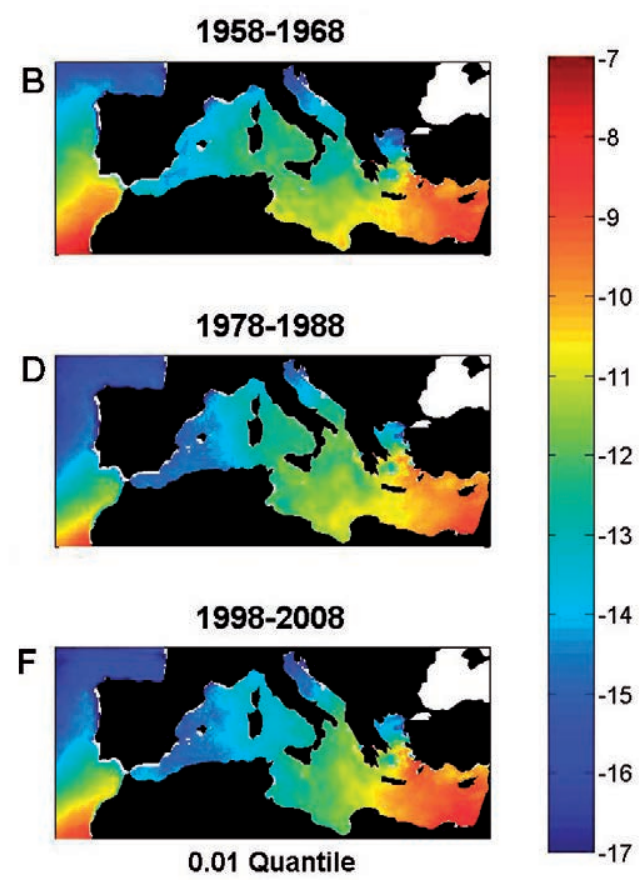

FIG. 8. - As in Figure 5, but for the 1st percentile of RSS time series

\section{Extreme events}

The extreme events are characterized through the 99th percentile for positive surges and through the 1 st percentile for negative events. The spatial distribution of positive extremes (Fig. 7) shows a latitudinal gradient similar to the distribution of STD (Fig. $4 \mathrm{~A})$, with stronger events in the northern half of the model domain and weaker events in the southern half. When the whole period is used for the computations (hereafter named the reference distribution), the 99th percentile ranges from $11.4 \mathrm{~cm}$ on the African coasts to $39.6 \mathrm{~cm}$ in the northern part of the Atlantic sector and in the northern Adriatic. The 99th percentile maps computed from 10-year periods have a similar spatial pattern, though values are slightly different between periods. Compared with the reference distribution, stronger events occurred during the 1958-1968 decade, especially in the western Mediterranean and in the Atlantic sector. In these areas, the 99th values were $15 \%$ higher than for the reference distribution. During the periods 1968-1978 and 1978-1988 the magnitude of the extreme events was very similar to the reference values. During the period 1988-1998 there was a generalized decrease of about $10 \%$ in comparison with the reference values, a decrease that extended to the period 1998-2008 except in the western Mediterranean and in the northern Adriatic, where it was about $20 \%$.

The spatial distribution of negative extremes is similar to that obtained for positive extremes (see Fig. 8 a) but with the opposite sign: stronger negative events are found in the northern half of the domain, while weaker ones are found in the southern half. The main differences between the positive and negative extreme distributions are obtained in the African Atlantic area, where negative events are especially weak (values around $-8.5 \mathrm{~cm}$ ) and in the Adriatic and Aegean seas, where negative extremes are more marked (values up to $-22.8 \mathrm{~cm}$ ). It is interesting to note that the range of negative surges is $14.5 \mathrm{~cm}$, while the range of positive surges is $28.5 \mathrm{~cm}$. In other words, the spatial distribution of negative events is more homogeneous than the distribution of positive events.

The distributions of negative extreme events obtained for different 10-year periods show similar patterns, but significantly different values. During the periods 19581968 and 1978-1988 the magnitude of negative events was fairly similar to the reference values (differences of only $\pm 5 \%$ ). The period $1968-1978$ shows the smallest negative events of all the hindcast period, with an averaged reduction in the magnitude of the extremes of about $20 \%$ over the whole domain except in the northern part of the Atlantic sector, where the change was only about $10 \%$. The opposite situation is found during the period 1988-1998, when the magnitude of the extreme events increased by $20 \%$ in the central Mediterranean, $10 \%$ in the western and eastern basins and only $5 \%$ in the Atlantic sector. Finally, in 1998-2008 the magnitude of the extreme negative events was again very similar to that of the reference situation.

\section{DISCUSSION}

The new VANI2-ERA hindcast provides an updated database (1958-2008) of sea-level residuals for southern Europe. It also shows better skills than other existing databases, although there are no great differences from the widely used HIPOCAS database, which 
covers the period 1958-2001. When compared with the longest tide gauge records (which include not only the atmospheric component of sea level but also the steric and mass components), the VANI2-ERA hindcast shows an averaged RMSE of $5.1 \mathrm{~cm}$, an averaged correlation of 0.84 and an averaged explained variance of $70 \%$. The worst performance of the model is at Venezia station, probably because of the quality of the winds in that region. Sea-level variability in the northern Adriatic is strongly affected by the wind, and in that region the wind is strongly modulated by the local steep orography (Cushman-Roisin et al. 2001). Therefore, the spatial resolution of the atmospheric model $(\sim 50 \mathrm{~km})$ may not be enough to properly reproduce the spatio-temporal variability of local winds.

Different hindcasts generated with different ocean models and atmospheric forcings show a similar relative performance between stations. That is, the stations where the VANI2-ERA hindcast shows a poorer performance are the same as those where all the other hindcasts also show the poorest performances. This suggests that at certain locations the sea-level variability may be significantly affected by other mechanisms in addition to the mechanical atmospheric forcing (i.e. steric or mass contributions) even at intra-seasonal scales.

Concerning extreme events, VANI2-ERA underestimates their strength. The model values are $10 \%$ smaller than observed positive surges and $17 \%$ smaller (in magnitude) than observed negative extreme events. This feature is common to all the hindcasts and was already discussed by Ratsimandresy et al. (2008), who suggested that the spatial resolution of the wind fields provided by the atmospheric models could be too coarse to correctly reproduce local winds. The temporal resolution is also likely to play a role.

The model performance (in terms of explained variance) is very similar when the total signal and the signal for the 3-30 days and 30-365 days bands are compared. For the 1-3 days band, however, the performance of the hindcast is worse at all the analysed stations, with a variance reduction of less than $65 \%$. In the 1-3 days band, wind is expected to play a significant role (i.e. more important that at lower frequencies, where atmospheric pressure dominates sea-level variability). This result therefore again suggests the low skills of the wind forcing, which might be underestimating, for instance, wind gust intensities and other small spatiotemporal features.

The hindcasts of RSS are often used to study the atmospheric component of sea-level variability of the past decades, especially during periods with little observational coverage (e.g. the pre-altimetric period). However, the quality of the atmospheric forcing during the last few decades may be lower than at present because of the smaller number of observations used to generate the atmospheric reanalysis. The comparison of the VANI2ERA hindcast with the four longest tide gauge records has certainly shown that the errors are non-stationary, and that changes in time can be of up to $50 \%$ of the total
RMSE. However, the quality of the hindcast does not show a clear trend, and the time evolution of the errors at different sites is not correlated, suggesting that the quality of the atmospheric forcing cannot explain the observed evolution of errors. Conversely there is a good agreement between the time evolution of the RMSE and the time evolution of sea level variability, suggesting that the variability in the hindcast errors is mostly induced by an increase in the variability of the fields. That is, if the sea level signal is stronger, the same relative error will lead to larger RMSE.

The comparison of different RSS hindcasts obtained using different models and different atmospheric forcings has given some insights into the modelling requirements of a RSS hindcast for southern Europe. As expected, the IB simulation is the worst one, confirming that the IB approach is not accurate enough in the Mediterranean for periods shorter than a few days (Garret 1983, Garret and Majaess 1984). The main reason is that the Strait of Gibraltar limits the mass flow that would be necessary for the basin sea level to adjust isostatically to atmospheric pressure changes. The absence of the wind forcing in the IB approach is also an important shortcoming in coastal areas (i.e. compare DAC with IB).

The hindcast with the second poorest performance is DAC. The spatial resolution and the physics of the ocean model used in DAC are comparable to those of VANI2-ERA or HIPOCAS. The forcing resolution is also comparable in the two products. However, as mentioned in the Methods section, DAC uses inverse barometer for frequencies lower than 20 days. Therefore, wind effects at these frequencies are not included in DAC though they may contribute to sea level variability in coastal areas. Alternatively, the quality of ECMWF atmospheric product used to force the model in DAC may also be lower than ARPERA. However, this extent merits further investigation.

The validation carried out in this work has allowed us to estimate the hindcast quality in terms of variability and extreme events. Conversely, the validation of the trends was not possible. The main reason is that separating the contribution of the different components of sea-level trends (i.e. steric, mass, and atmospheric) from tide gauge records is very difficult. At intra-seasonal scales we can argue that the atmospheric component is the dominating contribution, but this is no longer true for long-term trends. Actually, most previous estimations of sea-level trends in southern Europe have followed the opposite approach: the atmospheric contribution has first been derived, e.g. from HIPOCAS, and the other components have been inferred thereafter (see for instance, Tsimplis et al. 2005, Marcos and Tsimplis 2007, Calafat et al. 2010). Conversely, there are different works comparing the trends obtained from different models. Pascual et al. (2008) compared the atmospherically induced sea level trends computed for the period 1993-2001 from HIPOCAS and DAC, showing that the differences between them could be up to $2 \mathrm{~mm} / \mathrm{yr}$ for that period (note that the length of 

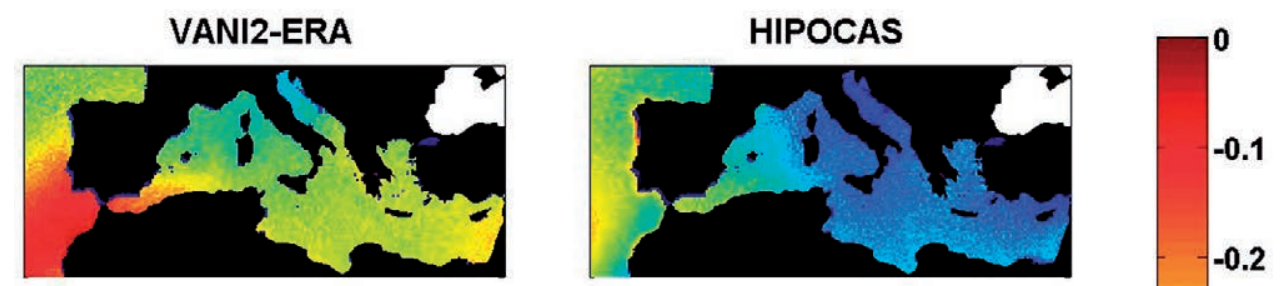

IB-ARPERA
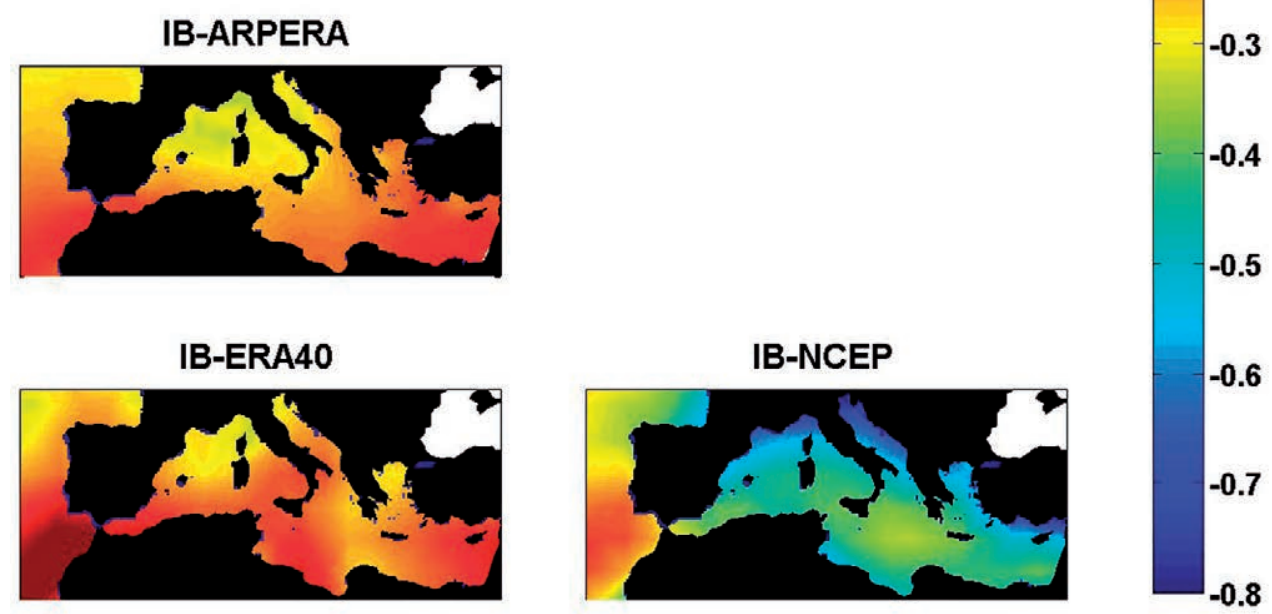

FIG. 9. - Sea-level trends (mm/yr) for the period 1958-2001 computed from different datasets. (Top left) VANI2-ERA, (top right) HIPOCAS, (middle left) Inverse barometer from ARPERA SLP, (bottom left) Inverse barometer from ERA40 SLP, (bottom right) Inverse barometer from NCEP SLP. The statistical accuracy of the trends is $0.1 \mathrm{~mm} / \mathrm{yr}$ on average. A colour version of this figure may be found in the online electronic manuscript

the period is only 8 years). From the results of Pascual et al. (2008), Tsimplis et al. (2011) inferred that the uncertainty in the atmospheric component of sea-level trends for a 40-year period may be of the order of 1 $\mathrm{mm} / \mathrm{yr}$. Here we have compared the overall trends obtained from VANI2-ERA and from HIPOCAS. Figure 9 shows the sea-level trends obtained from different datasets for the common period 1958-2001. The values obtained from VANI2-ERA and HIPOCAS are different: VANI2-ERA shows less negative trends $(-0.3 \pm 0.1$ $\mathrm{mm} / \mathrm{yr}$ on average) than HIPOCAS $(-0.5 \pm 0.1 \mathrm{~mm} / \mathrm{yr}$ on average). The spatial distribution is very similar in the Mediterranean but not in the Atlantic.

In order to investigate the origin of the differences between the two hindcasts, the sea-level trends directly induced by the atmospheric pressure obtained from the ARPERA atmospheric model can be checked (Fig. 9, middle panel). The resulting field shows less negative trends than VANI2-ERA $(-0.2 \pm 0.05 \mathrm{~mm} / \mathrm{yr}$ on average). The spatial pattern is similar to that of VANI2ERA, but there is an almost constant bias of $0.15 \mathrm{~mm} /$ yr between the two trend distributions. Assuming that at low frequencies the IB response is a good approximation, we can conclude that the differences between VANI2-ERA and ARPERA IB reflect the effects of the wind on sea level. This finding is consistent with the results of Fukumori et al. (2007), who suggested that winds at Gibraltar may affect the long-term evolution of the Mediterranean Sea level. A more detailed quantification of the wind contribution to long term trends requires dedicated numerical experiments that are beyond the scope of this paper.

Unfortunately, the atmospheric downscaling used to generate the HIPOCAS hindcast cannot be analysed. Instead, we checked the trends of the IB response to ERA40 and NCEP, which are the "parent" reanalysis of ARPERA and HIPOCAS, respectively (see the lower panel of Fig. 9). The trends obtained from NCEP are more negative than those from ERA40 (on average, $-0.4 \pm 0.1 \mathrm{~mm} / \mathrm{yr}$ and $-0.2 \pm 0.1 \mathrm{~mm} / \mathrm{yr}$ respectively). It is worth noting that the difference between ERA40 and NCEP is almost the same as the difference between VANI2-ERA and HIPOCAS. Moreover, ERA40 trends are close to ARPERA trends, suggesting that the downscaling follows the long-term evolution of its parent reanalysis. Summarizing, it seems that differences between VANI2-ERA and HIPOCAS sea-level trends are caused by inconsistencies between the parent reanalysis used to force the corresponding atmospheric model. Elucidating the reasons for the discrepancies between the two reanalyses is not easy and is presently under investigation. The consequence for sea level in southern Europe is that atmospherically-induced trends have an associated uncertainty of at least $0.2 \mathrm{~mm} / \mathrm{yr}$ for the second half of the $20^{\text {th }}$ century, mostly due to inconsistencies in the parent reanalysis used to force the atmospheric model. This is twice the uncertainty estimated by Tsimplis et al. (2011).

The updated coverage of the VANI2-ERA hindcast has also allowed the characterization of atmospherically-induced sea-level variability during recent years 
(not covered by HIPOCAS) and its comparison with the previous decades. The variability (quantified in terms of the STD) of the decade 1998-2008 has been the smallest of all the ten-year periods analysed: $10 \%$ smaller than for the overall period in the central and western Mediterranean and about 5\% smaller in the rest of the domain. Concerning the decadal trends, which are a measure of the decadal variability, the mechanical atmospheric forcing has induced an average positive trend of $+0.11 \pm 0.05 \mathrm{~mm} / \mathrm{y}$ during this last decade, smaller than for the previous period (1988-1998) when they had an average value of $+2.31 \pm 0.08 \mathrm{~mm} / \mathrm{y}$. When added to the trends of the second half of the $20^{\text {th }}$ century, the last decade contributes to the smoothing of the overall negative trends. Finally, the recent period is also characterized by a $20 \%$ reduction in the magnitude of positive extreme events and by almost no change in the negative extreme events.

In order to explain the observed changes, the first candidate is the main natural mode of atmospheric variability in the region: the North Atlantic Oscillation (NAO). A clear correlation has been found between the NAO index and sea level in the NE Atlantic (Wakelin et al. 2003, Woolf et al. 2003, Yan et al. 2004); the link is mostly due to atmospheric pressure and wind effects, but a smaller thermosteric contribution has also been suggested (Tsimplis et al. 2006). In the Mediterranean, sealevel variability has also been related to the NAO, mainly through the effect of the atmospheric pressure (Gomis et al. 2008). Positive (negative) phases of the NAO imply higher (lower) atmospheric pressure in southern Europe and hence a sea-level decrease (increase). Therefore, the decadal trends of the NAO index can be explored to see whether there is any correspondence with the estimated sea-level trends shown in Figure 6. (The monthly NAO index is obtained from the Climate \& Global dynamics group (http://www.cgd.ucar.edu/cas/jhurrell/indices. html; see also Hurrel and Deser 2009).) The results show a good agreement between the decadal trends of the NAO index and the decadal trends of sea level (Fig. 10). Positive NAO trends during the period 1968-1978 are consistent with the strong negative sea-level trends found for the same period. Conversely, the negative NAO trends of the period 1988-1998 are also consistent with the large positive sea-level trends obtained from the hindcast. Finally, the small negative NAO trends of the period 1998-2008 are in good agreement with the small positive sea-level trends obtained from the hindcast.

The NAO is likely to also play a role in the decadal variability of the sea-level STD and extreme events. During negative phases of the NAO, the track of the cyclones generated in the north Atlantic is displaced southwards across the Mediterranean. Therefore, i during these phases the sea-level variability is expected to increase and extreme events be stronger. However, no clear relationship has been found between the decadal evolution of the NAO index and the sea-level STD or the extreme events, so the role of the NAO in their decadal evolution is left as a speculation.

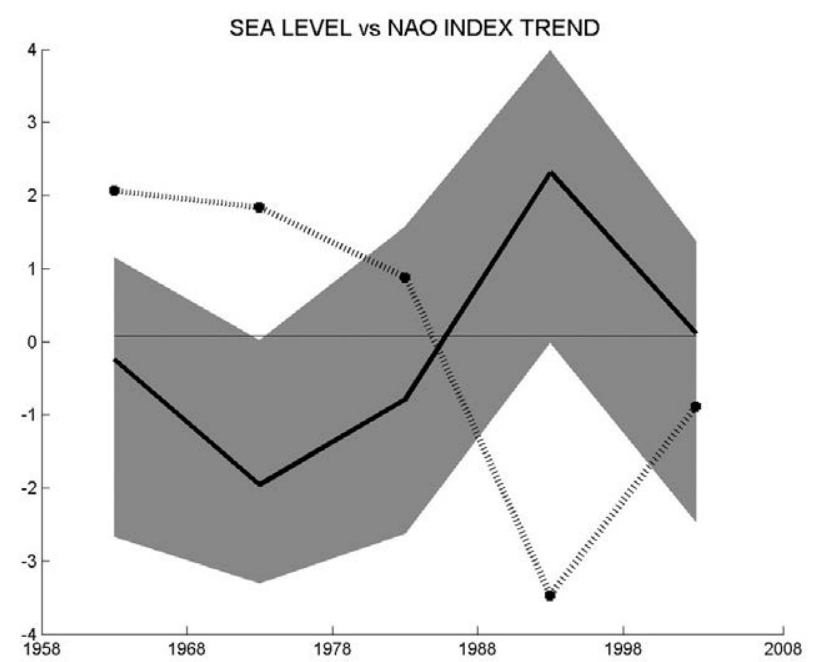

FIG. 10. - Decadal trend of the NAO index (dashed line; 50.NAO units/yr) and sea-level decadal trends (solid; in $\mathrm{mm} / \mathrm{yr}$ ). The shaded area indicates the range of sea-level trends obtained over the whole model domain.

\section{CONCLUSIONS}

The VANI2-ERA hindcast of sea-level residuals for Southern Europe was generated using the HAMSOM ocean model and covers the period 1958-2008. The ocean model was forced with the ARPERA atmospheric hindcast, a dynamical downscaling of ERA40. The quality of VANI2-ERA is higher than that of other existing hindcasts when compared to tide gauge observations. The time evolution of the hindcast quality was also assessed. In terms of explained variance it shows a rather constant performance for the 50-year period of simulation; during periods of higher sea-level variability the RMSE are higher. An analysis at different frequency bands has shown that the hindcast quality is significantly lower in the 1-3 days band, probably because of inaccuracies in the wind field. The trends obtained with VANI2-ERA were compared with the trends obtained with the HIPOCAS, the reference dataset for most studies on sea-level variability in Southern Europe up to now. The comparison highlighted a problem in the ERA40 and NCEP reanalyses: the longterm trends in sea-level pressure obtained from the two reanalyses are not consistent, with doubled values in NCEP in comparison with ERA40 in Southern Europe. This is a very critical issue that must be investigated.

The extended length of the hindcast was also used to characterize the atmospherically induced sea-level variability in Southern Europe during the last few years. Results show that the period 1998-2008 was characterized by a reduction in sea-level variability in comparison with the overall period 1958-2008, a reduction in positive extreme events and small positive trends in comparison with the overall negative trends obtained for the second half of the $20^{\text {th }}$ century.

Finally, it is important to mention that the VANI2ERA hindcast is the first milestone of the forthcoming 
SIMAR-54 database, which will include promising new hindcasts based on high-resolution atmospheric forcing ( $25 \mathrm{~km} / 1$ hour) being generated by the Spanish Meteorological Agency (AEMET), sea-level reconstructions for the 20th century (Calafat and Jordà 2011) and sea-level projections for the $21^{\text {st }}$ century under different climate change scenarios (e.g. Jordà et al. 2012, Marcos et al. 2011). If finally required, existing hindcasts could also be assembled in order to produce an optimal product.

\section{ACKNOWLEDGEMENTS}

This study was carried out in the framework of the projects VANIMEDAT-2 (CTM2009-10163-C02-01, funded by the Spanish Marine Science and Technology Program and the E-Plan of the Spanish Government) and ESCENARIOS (funded by the Agencia Estatal de METeorología). G. Jordà acknowledges a "JAE-DOC" contract funded by the Spanish National Research Council (CSIC). The authors would like to thank S. Somot and M. Déqué for running the ARPEGE-Climate simulations and Météo-France for providing the model outputs. M. Marcos and Begoña Pérez-Gómez kindly provided the processed tide gauge data. The DAC outputs were produced by CLS Space Oceanography Division using the MOG2D model from LEGOS. We also thank M. Tsimplis for his suggestions to improve the manuscript.

\section{REFERENCES}

Álvarez-Fanjul E., Pérez-Gómez B., Rodríguez-Sánchez-Arévalo I. 1997. A description of the tides in the eastern North Atlantic. Prog. Oceanogr. 40: 217-244.

Backhaus, J.O. 1983. A semi-implicit scheme for the shallow water equations for application to shelf sea modelling. Cont. Shelf Res. 2: 243-254.

Carrère L., Lyard F. 2003. Modelling the barotropic response of the global ocean to atmospheric wind and pressure forcing - comparisons with observations, Geophys. Res. Lett., 30: 1275.

Calafat F.M., Marcos M., Gomis D. 2010. Mass contribution to the Mediterranean Sea level variability for the period 1948-2000. Global Planet. Change 73: 193-201.

Calafat, F.M., Jordà G. 2011 A Mediterranean Sea Level reconstruction (1950-2010) with error budget estimates. Global Planet. Change 79: 118-133.

Cushman-Roisin B., Gacic M., Poulain P.-M., Artegiani A. (Eds.) 2001. Physical Oceanography of the Adriatic Sea. Springer, New York.

Déqué M., Piedelievre J. 1995. High resolution climate simulation over Europe, Clim. Dyn. 11: 321-339.

Déqué, M. 2007. Frequency of precipitation and temperature extremes over France in an anthropogenic scenario: Model results and statistical correction according to observed values. Global Planet. Change 57: 16-26

Fukumori I., Menemelis D., Lee T. 2007. A near-uniform basinwide sea level fluctuation of the Mediterranean Sea. J. Phys. Oceanogr. 37: 338-358. Garrett C. J. R. 1983. Variable sea level and strait flows in the Mediterranean:A theoretical study of the response to meteorological forcing. Oceanol. Acta. 6: 79-87.

Garrett C. J. R., Majaess F. 1984. Nonisostatic response of sea level to atmospheric pressure in the eastern Mediterranean, J. Phys. Oceanogr. 14: 656-665.

Gibson, J., Kållberg P., Uppala S., Hernandez A. and Serano E. 1997. ERA description, in Re-anal, Proj. Rep. Ser., European Center for Medium-Range Weather Forecast, Reading, U. K.
Gomis D., Tsimplis M.N., Martín-Míguez B., Ratsimandresy A.W., García-Lafuente J., Josey S.A. 2006. Mediterranean Sea level and barotropic flow through the Strait of Gibraltar for the period 1958-2001 and reconstructed since 1659. J. Geophys. Res. 111: C11005.

Gomis D., Ruiz S., Sotillo M. G., Álvarez-Fanjul E., Terradas J. 2008. Low frequency Mediterranean sea level variability: the contribution of atmospheric pressure and wind. Global Planet. Change 63: 215-229.

Herrmann M. J., Somot S. 2008. Relevance of ERA40 dynamical downscaling for modeling deep convection in the Mediterranean Sea, Geophys. Res. Lett 35: L04607.

Hurrell, J.W., Deser C. 2009. North Atlantic climate variability: The role of the North Atlantic Oscillation. J. Mar. Syst. 78: 28-41,

Jordà. G., Gomis D., Álvarez-Fanjul E., Somot. S. 2012. Atmospheric contribution to Mediterranean and nearby Atlantic sea level variability under different climate change scenarios. Global Planet. Change 80-81: 198-214.

Marcos M., Tsimplis M.N. 2007. Variations of the seasonal sea level cycle in Southern Europe. J. Geophys. Res. 112: C12011.

Marcos M, Tsimplis M. N. (2007). Forcing of coastal sea level rise patterns in the North Atlantic and the Mediterranean Sea. Geophys. Res. Lett 34: L18604.

Marcos M., Tsimplis M.N., Shaw A.G.P. 2009. Sea level extremes in southern Europe, J. Geophys. Res. 114: C01007.

Marcos M., Jordà G., Gomis D., Pérez B. 2011. Changes in storm surges in southern Europe during the $21^{\text {st }}$ century. Global Planet. Change 77: 116-128.

Nicholls R.J., Leatherman S.P.1994. Global sea-level rise. In: Strzepek, K., Smith, J.B. (eds.), Climate Changes: Potential Impacts and Implications. Cambridge Univ. Press.

Pascual A., Marcos M., Gomis D. 2008. Comparing the sea level response to pressure and wind forcing of two barotropic models: Validation with tide gauge and altimetry data, J. Geophys. Res., 113: C07011.

Pawlowicz R., Beardsley B., Lentz S. 2002. Classical Tidal "Harmonic Analysis Including Error Estimates in MATLAB using T_TIDE".Comput. Geosci. 28: 929-937.

Ratsimandresy A.W., Sotillo M.G., Carretero J.C., Álvarez-Fanjul E., Pérez Gómez B., Hajji H. 2008. A 44-year (1958-2001) sea level residual hindcast over the Mediterranean Basin. Phys. Chem. Earth 33: 250-259.

Simmons A., Gibson J. 2000. The ERA-40 project plan, ERA-40 project report series, Tech. Rep. 1, ECMWF, Shinfield Park, Reading, UK, $63 \mathrm{pp}$.

Sotillo M.G., Ratsimandresy A.W., Carretero J.C., Bentamy A., Valero F., González-Rouco F. 2005. A high-resolution 44-year atmospheric hindcast for the Mediterranean Basin: contribution to the regional improvement of global reanalysis. Clim. Dynam. 25: $219-236$

Tsimplis M.N., Alvarez-Fanjul E., Gomis D., Fenoglio-Marc L., Perez B. 2005. Mediterranean Sea level trends: atmospheric pressure and wind contribution, Geophys. Res. Lett., 32: L20602.

Tsimplis M.N., Zervakis V., Josey S., Peneva E., Struglia M.V., Stanev E., Lionello P., Malanotte-Rizzoli P., Artale V., Theocharis A., Tragou E., Oguz T. 2006. Changes in the oceanography of the Mediterranean Sea and their link to climate variability. In: Lionello, P., Malanotte-Rizzoli, P., Boscolo, R. (eds.), Mediterranean Climate Variability. Elsevier. ISBN: 0-444-52170-4, p. 438.

Tsimplis M., Marcos M., Colin J., Somot S., Pascual A., Shaw A.G.P. 2009. Sea level variability in the Mediterranean Sea during the 1990 s on the basis to two $2 \mathrm{~d}$ and one $3 \mathrm{~d}$ model. $J$. Mar. Sys., 78: 109-123.

Wakelin S.L., Woodworth P.L., Flather R.A., Williams J.A. 2003. Sea-level dependence on the NAO over the NW European continental shelf. Geophys. Res. Lett. 30: 1403.

Woolf D., Shaw A., Tsimplis M. 2003. The influence of the North Atlantic oscillation on sea level variability in the North Atlantic region. Global Atmos. Ocean Syst. 9: 145-167.

Yan Z., Tsimplis M.N., Woolf D. 2004. An analysis of relationship between the North Atlantic oscillation and sea level changes in NW Europe. Int. J. Climatol. 24: 743-758.

Received February 10, 2011. Accepted January 17, 2012.

Published online August 5, 2012. 